\title{
High Tech, High Fear?
}

Tracy Reynolds, Ashland University, USA

Sivakumar Venkataramany, Ashland University, USA

\begin{abstract}
Outsourcing a wide variety of information technology jobs overseas has become a recent trend due to the availability of well-educated and inexpensive work force abroad, particularly, in India. Back-office functions in financial services, medical transcriptions in health care industry and call centers for several industries are a few examples where less important and mechanical functions have been transported to less developed countries. While fears loom large on account of anticipated job losses, the changing landscape of the information technology field can bring many benefits to the American workforce by a better understanding of global competitors, strategically planning for future employment needs, and also promote continuing education for desirable skill sets.
\end{abstract}

\section{INTRODUCTION}

$\mathrm{n}$ recent decades the world has witnessed the evolution of the information age. The United States has played a major role as a supplier and as a consumer of innovative products. In the last decade alone, many routine activities have been enhanced by high technology systems like direct deposit payroll
systems, self-checkout counters, and internet banking. As the American workforce embraces the new age and its plethora of employment opportunities, there are now fears that many prized jobs may be in jeopardy due to the globalization of the information technology field. The fears are driven by the regularity of reports that many Fortune 500 companies are moving large numbers of positions overseas, especially many of the back-office functions in financial services, medical transcriptions in health care industry and call centers for several industries. Outsourcing a wide variety of information technology jobs overseas has become a recent trend due to the advantage of inexpensive work forces and bringing alongside a new learning experience in management of human capital, protection of intellectual property and building leak-proof firewalls of improved security. The changing landscape of the information technology field can bring many benefits to the American workforce by a better understanding of global competitors, strategically planning for future employment needs, and also promote continuing education for desirable skill sets.

\section{TWENTY FIRST CENTURY TECHNOLOGY}

For most of the world, information technology now plays an enormous role in virtually every function of human life. Even an activity such as reading a newspaper has been tainted by the touch of information technology. The newspaper articles were written on a word processing software application, sent via e-mail attached with a digital photo. The newspaper was formatted using a desktop publishing package and printed using advanced laser printers. Although the paper itself may still be delivered the old fashioned way, a customer can pay their bill and tip the delivery person online. Also, customers may have the option to download the current publication onto their PDA for viewing purposes. The advancements of the business process have brought greater efficiency and reliability to the newspaper business as well as convenience to the reader. This is just a simple example of the capacity of the information revolution and how the need for greater technology is fueling the world. It would be challenging to think of how current tasks would be performed without the aid of modern technology.

Information technology began appearing in the workplace during the mid to late twentieth century. The paradigm shift began when it was recognized that computer devices could aid and replace workers and the business functions they manually performed. Clerical jobs were one the first to see the effect by automations of data entry and data processing. Although many traditional jobs were eliminated, several new positions were born as the need 
for the creation and maintenance of hardware and software applications were established. Automation also drastically reshaped the manufacturing industry as it enhanced order processing, production scheduling, and inventory control. The birth of computer automation gave way to the information technology field. It is amazing to think that in less than 50 years an entire employment classification has been created to accommodate a new wave of work. The addition of computer related occupations accounted for 2.9 million jobs in the United States according to the Bureau of Labor Statistics (2004)

Listed below are current jobs the Bureau of Labor Statistics classifies as being associated with the information technology field (2004)

Computer Programmers write, test, and maintain the detailed instructions, called programs, which computers must follow to perform their functions. They also conceive, design, and test logical structures for solving problems by computer.

Computer Software Engineers apply the principles and techniques of computer science, engineering, and mathematical analysis to the design, development, testing, and evaluation of the software and systems that enable computers to perform their many applications.

Systems Analysts solve computer problems and apply computer technology to meet the individual needs of an organization. They help an organization to realize the maximum benefit from its investment in equipment, personnel, and business processes.

Computer Support Specialists provide technical assistance, support, and advice to customers and other users. This occupational group includes technical support specialists and help-desk technicians. These troubleshooters interpret problems and provide technical support for hardware, software, and systems.

Network Systems and Data Communications Analysts are needed to design, test, and evaluate systems such as local area networks (LANs), wide area networks (WANs), the Internet, intranets, and other data communications systems. Network systems and data communications analysts perform network modeling, analysis, and planning; they also may research related products and make necessary hardware and software recommendations.

Internet Developers or Web Developers, also called Web designers, are responsible for day-to-day site design and creation.

Computer Scientists work as theorists, researchers, or inventors. The higher level of theoretical expertise and innovation they apply to complex problems and the creation or application of new technology distinguishes their jobs.

Database Administrators work with database management systems software and determine ways to organize and store data. They identify user requirements, set up computer databases, and test and coordinate modifications to the systems.

All of the occupations listed above work together in a harmonious way. A dynamic relationship exists between the programmer, the database administrator and the systems analyst. The analyst understands the process the programmer will automate and the data necessary to fulfill the business requirements. The analyst conveys the business needs to the programmer so he or she is able to work through the technical needs. As the programmer works on the task, issues may come up that the analyst will need to address for further action. Any misunderstandings between the needs of the analyst and work created by the programmer can be disastrous.

The advancement of computer hardware has inversely affected the relationship between the quality and quantity of software applications. In recent times, the cost of the computer hardware far outweighed the cost of labor to operate the technology. Now as the cost of hardware is much lower, the value of the worker manipulating the functionality of the computer system is much more valuable. The understanding of the resources is the key to 
well organized and planned applications that are crucial to system development. A critical component of the information age is the importance of advanced design, not the value of cost efficient labor.

\section{GLOBAL COMPETITION}

As the fields listed above began to carve a new niche into society with the advent of new technologies and efficient processes, other countries began to take note of the power created by the new industry. When the Japanese Economic Planning Agency surveyed 110 critical technologies in 1991, it concluded that American firms dominated 43 of them, Japanese firms dominated 33, and European and other miscellaneous firms dominated 34. One of the reasons why America remains dominant in so many areas of technology is its strong scientific community. The United States has more scientists and engineers, spends more money on scientific research, and publishes more scientific papers than Great Britain, France, Germany, and Japan put together (Moran \& Harris, 1993). In the years since this research was completed, many countries have given the Unites States competition as being the technology superpower. See the High-Technology Exports chart to view where the United States stands compared to other high-tech producers. Although the United Kingdom and Japan may be leaders in exports, North America is the global leader of IT software and services producing $43 \%$ of the industries total revenue. The chart on Global IT Service and Software by Region offers regional positioning in this area.

The dominance the United States once had is being challenge on two fronts. First, foreign countries are producing technology goods equal to those produced by American firms. Second, nations around the world are providing American companies with foreign workers armed with solid technical skills. The outsourcing of American jobs has become a great threat. Key technological developments in areas such as telecommunications have paved the way for work to be done away from home operations. American companies recognized this as an opportunity to cut labor costs by moving certain jobs overseas. The rush to shift high labor costs in the United States to lower markets around the world has grown at an alarming rate. Offshore work environments were almost impossible before the mid nineties due to the costs and efforts associated with having to transport punch cards, cartridges, and space consuming hardware. Now that high-speed communication is widely available, long distance shops can operate via e-mail, instant messaging, and teleconferencing.

As foreign countries compete for outsourced jobs, many American workers are left wondering about the fate of their current positions. The trend for moving jobs overseas began picking up speed in the last several years when companies began tighten their belts by looking for ways to cut costs and stretch budgets. The end of the dot com boom, the backlash of the spending frenzy resulting from Y2K, and the post millennium slow-down contributed to the need for managers to find creative ways to address IT needs. The United State's open market, free trade, and competitive environment poised American firms in a strong position to employ global resources. Once connections were made overseas, the potential benefits of reducing labor costs were recognized. The United States learned an important lesson during this time. While just a few short years ago a shortage of human capital was noted. It was then addressed by searching the global work force for resources to fill the gap left by the shortage. Then, the problem was triumphed by managing the human resources to combat the problem with rewarding success.

\section{EFFECTS ON EMPLOYMENT}

As American firms look outside the United States to satisfy employment needs, it is uncertain what will happen to the U.S. economy and labor force. The feelings of uneasiness seem eerily familiar to those from the previous decades regarding manufacturing jobs. The new requirement in the movement of jobs overseas is the level of skill needed for the jobs. When manufacturing jobs were relocated to areas with cheaper labor costs, the type of employment required was unskilled labor. However, the jobs being sourced overseas today are white-collar, skilled labor positions. The differences between the two usually amount to a college degree and or several years of industry experience. The outlook appears gloomy when a big five accounting firm announces a move that would seek foreign employment for several thousands of skilled positions. The search for overseas outlets has grown to a level that now supports firms that aid in the information technology outsourcing transition. Consulting services provide support and industry knowledge in transferring key business functions from home operations to foreign soil. 
One idea gives rise to a new way of thinking of the job losses in America. Advancements in productivity do not appear to have an effect on total unemployment. See the U.S. Productivity vs. Employment chart for more information on how productivity continues to increase while unemployment remains unchanged. Technology helps to create greater efficiency in business. Higher profits should then follow the increases in efficiencies. The profitable business helps to make the industry stronger as a whole, which then promotes new growth and employment opportunities within the information technology field.

The manufacturing industry capitalized on the cheap labor force in other countries to reduce costs. It should be no surprise then that the globalization of the information technology field is creating a storm of concerns and negative hype. The implementation of NAFTA seemed just as appalling to General Motor's employees as offshore programming does to developers in Silicon Valley and beyond. A key idea that the new wave of threatened workers may be able to understand is that large layoffs, or transfers of employment, may not be as gloomy as once thought in the manufacturing age. Although employment loss is devastating to the employee, the overall economic outcome may be beneficial for the entire domestic workforce. By combining the current low inflation rates with productivity gains, the U.S. economy should benefit from increases in real wages.

\section{EMPLOYMENT GAP}

Are American jobs really being sent overseas or are overseas workers helping to fill an employment gap? In 2002, a Forrester lead researcher, John McCarthy issued a highly publicized report that predicted, "Over the next 15 years, 3.3 million US service industry jobs and $\$ 136$ billion in wages will move offshore to countries like India, Russia, China, and the Philippines. The IT industry will lead the initial overseas exodus". The information sounds shocking until it is noted that, total employment is projected to increase by 21.3 million while the civilian labor force is only projected to increase by 17.4 million. (Bureau of Labor Statistics) When the figures are compared, if using foreign workers fills 3.3 million of the 21.3 million jobs and the new civilian workers account for 17.4 then there will be over a half a million jobs unfilled. It becomes apparent that using foreign workers to bridge the employment gap is necessary.

\section{ECONOMIC DEPLETION}

If a leading sector of our economy is technology and there is a failure meeting the technological demands, the hope for a prosperous economy is poor. The Office of Technology Policy, a division of the Department of Commerce released a report called "America's New Deficit: The Shortage of Information Technology Workers" The report notes, "Since information technology is an enabling technology that affects the entire economy, our failure to meet the growing demand for information technology professionals could have severe consequences for America's competitiveness, economic growth, and job creations."(1997) Information technology jobs account for almost all of the jobs on The Fastest Growing Occupations table.

The high level of salary an information technology worker commands is largely due to the shortage of qualified workers. Look at The Average Salary by Occupation table, which indicates where the typical information technology professional fits in with other occupations. The upward pressure on salaries is the result of the competition for the skilled IT worker. The lack of talent drives up the cost of employing skilled employees, in turn, the increased cost of labor prompts the employer to seek elsewhere to find needed employees.

\section{INFORMATION TECHNOLOGY EMPLOYMENT OUTLOOK}

As the growth of the information technology field continues at an unprecedented rate, the level of employment needed to keep up with the field has grown to an alarming number. "Employment in computer systems design and related services will grow by 54.6 percent and add more than one-third of all new jobs in professional, scientific, and technical services. Employment growth will be driven by the increasing reliance of businesses on information technology and the continuing importance of maintaining system and network security" (Tomorrow's Jobs). At the end of 2003, the global software and service industry reached a value of $\$ 904$ billion. The industry 
also grew at an annual compounded rate of $10.5 \%$ between 1999 and 2003 . This industry group is projected to swell to 1.4 trillion in value by 2008 (Datamonitor).

Several issues contribute to the shortage of information technology workers. First, most information technology field positions require a four year degree. Second, the transition from another occupation to an information technology position can be difficult because of the amount of training required for highly skilled job is time consuming. Lastly, the desired skill sets for an information technology worker changes at a rate much greater than any other field making it difficult for even a seasoned IT worker to posses the needed qualifications. The lesson of the information age is "a valued skill set is not a guarantee for employment longevity". As the dynamics of the information technology industry change, so should the view of lifetime careers.

\section{FUTURE EDUCATION}

Advanced technologies have the potential to provide knowledge and training when and where it is needed, while boosting the productivity of learning and lowering its cost. Such technologies have the potential to boost the capabilities, productivity, and flexibility of American workers. Former Secretary of Education, Rod Paige, stressed the need for innovation in education. "America's prosperity in the 21 st century rests largely upon the success of our education system to equip citizens with the knowledge and skills needed to thrive in our global economy. As innovation drives economic growth, it is incumbent upon us to explore innovative means of improving learning and instruction. Education is no longer limited to our early years; it is now a life-long pursuit and we need new systems and tools to meet this need. We are barely scratching the surface of technology's potential to transform the way we learn." (2003) "America's competitiveness in the knowledge-based economy depends on the skills and abilities of our workforce," said Under Secretary Bond. "In the face of intense global competition, nations around the world are competing for jobs and economic growth by developing a world class workforce. To compete and win, our workers need broad and rapid access to high-quality knowledge and skills development from K to gray" (2003)

\section{OFFSHORE EMPLOYMENT}

The decreasing costs and improved functionality of communication mediums allow businesses to take advantage of low wages in developing countries. Companies can use the differences in time zones to implement and improve operational functionality that spans over 24 hours and 7 days a week. Setting up shop a far distance from home also gives the organization an opportunity to source local materials and sell to local customers. By employing workers around the world, the United States stands to benefit by empowering a larger group of global consumers. Dell has become an industry leader in moving technical call center positions to India, which is helping to promote a better way of life for the new Indian working class. Organizations may also have a more direct focus that is designed to move critical technical operations overseas so they can concentrate more local resources on key business functions.

\section{AREAS FOR CONCERN}

Information technology professionals are quick to understand the front line battles being fought to find and keep qualified workers in the information technology field. Those industry professionals not only understand the human resource need, but also they are keenly aware of potential issues that may arise from globally sourcing IT workers. The decision to move or begin performing critical business processing in another country is very large and requires a high level of research and consideration. The feasibility to explore internationally should include management from the entire organization to concentrate on three areas of focus: true cost, potential risk, and longterm sustainability.

\section{True Cost}

Doing business in the United States has become challenging for most managers. The competitive atmosphere has caused many executives to look outside the American borders for cheaper means of producing their good or service. Measurements of viability for offshoring generally account for the following costs: labor, travel, 
training, licensing, communication, transportation, and management. If these costs together can be found elsewhere at a discount, management usually begins assessing the opportunity of going abroad. These easily quantifiable costs are a good starting point for determining if exploration should continue; however, there are many other details that are overlooked that never make it into the cost/benefit analysis.

When looking at international labor markets it is essential to recognize the differences that may offset the value of the sourced good. An organization may be able to find the right mix of qualified workers in an international market, but they must be able to produce the good at the standard of the organization. Development of poor software can increase a company's cost for support and it may also jeopardize customer relations. When evaluating the opportunity of going abroad, it may be extremely damaging if an organization does not have a clear understanding of the true cost of the IT function and the value returned on the service. By not correctly identifying the value of having correct data in a timely manner, a company may adversely offset operational costs in other areas. Also, if costs are measured where the IT workers and end users are working in the same building there may be a significant additional cost in end-user support as well as capturing initial business requirements for a new project when the two groups are on opposite sides of the world.

\section{Potential Risk}

Many people related to the information technology field have concerns in several areas of the trend to move technology jobs overseas. Besides the obvious concern for lost employment, issues such as data security have been adding fuel to the fiery debate about relocating IT jobs. Due to the lack of domestic development in the information technology field in the countries that American firms are seeking low wage employment, many of the countries have weak data privacy laws. In the United States, it has become obvious that the need for strict and carefully enforced privacy laws is of top priority. A downside to the growth of the information age is that identity theft and consumer fraud have sharply increased as a result of the easy accessibility to personal data stored by the government and private institutions. Legislative efforts may soon be taking an active role in helping the private sector decide what types of information can be transferred safely.

Another area that may compromise profitable operations overseas is the issue of protection of intellectual property and enterprise knowledge. Intellectual property rights are not as strictly enforced in some countries as they are in the United States. This can create a problem when foreign workers are being used to develop and test industry leading applications. The value of the proprietary investment in the key technology may outweigh the level of savings that may be received by working in a low wage market. An organization may become very vulnerable from strategic standpoint if their enterprise knowledge and trade secrets are compromised by unethical behavior in environments that do not condone such criminal acts.

\section{Future Sustainability}

A final area for concern lies with the issues that may arise when a business needs to sever the contractual relationship of business and terminate domestic workers in the foreign country. Legal issues between the organization and the host country may occur when the organization determines it is no longer profitable to continue operating the offshore outlet. A formal exit strategy is necessary to ensure that both the host country and the foreign company are specifically aware of the details of their engagement. Along with analyzing a long-term plan of financial feasibility, it would also be greatly beneficial to study the projections of future growth in this new market. A business would be wise to view the foreign venture as a stepping-stone for a future international presence rather than a short-term financial opportunity.

\section{CONCLUSION}

Legislative bodies and business managers will need to take into consideration the problems that most likely will occur due to the logistical issue of transporting large amounts of data and managing human resources on the other side of the globe. Also, they will need to take into consideration how data integrity, privacy, and intellectual property can be maintained when foreign workers access critical information and sensitive data while carrying out 
the employment duty they have been hired to do. While looking at ways to provide individual protection, careful foresight needs to be focused on not eliminating competitive advantages of foreign IT providers. Competitive protection measures would stagnate the technology efforts of the United States. By hindering our ability to perform in the global market we run the risk of loosing our dominance in the information technology field. Currently we are outsourcing information technology positions from outside the US for financial reasons, how will the world be shaped if we must outsource positions to gain higher quality resources? It has been noted that advancements in technology bring greater efficiencies, greater efficiencies bring higher profits, and high profits bring stronger markets. Successfully managing our ride on the technology wave will determine our future global economic position.

Will we see a steady stream of reports in the later part of the decade noting how companies lost great amounts of revenue and human capital through offshore outlets because they misjudged costs, experienced problems with data security or overestimated the capability of foreign workers? It is hoped that organizations and legislative bodies will plan well and test thoroughly to evaluate the overall benefit of foreign working environments. It is my hope that American information technology workers will be able to look to the future to see that planning for a future employment shortage now will bring a robust economy with continuing opportunities for future success.

Fastest Growing Occupations

Projected 2000-2010

\section{Occupation}

Software engineers, applications

Computer support specialists

Software engineers, systems

Network \& computer systems administrators

Network systems \& data communication analysts

Desktop publishers

Database administrators

Personal and home care aids

Computer systems analysts

Medical assistants

Social \& human service assistants

Physicians assistants

Medical records \& health information technicians

Computer \& information systems managers

Home health aids

Physical therapist aids

Occupational therapists aids

Physical therapist assistants

Audiologists

Fitness trainers \& aerobics instructors

\begin{tabular}{|c|c|c|c|}
\hline$\underline{2000}$ & $\underline{2010}$ & $\underline{\text { Number }}$ & Percent \\
\hline 380 & 760 & 380 & $100 \%$ \\
\hline 506 & 996 & 490 & $97 \%$ \\
\hline 317 & 601 & 284 & $90 \%$ \\
\hline 229 & 416 & 187 & $82 \%$ \\
\hline 119 & 211 & 92 & $77 \%$ \\
\hline 38 & 63 & 25 & $67 \%$ \\
\hline 106 & 176 & 70 & $66 \%$ \\
\hline 414 & 672 & 258 & $62 \%$ \\
\hline 431 & 689 & 258 & $60 \%$ \\
\hline 329 & 516 & 187 & $57 \%$ \\
\hline 271 & 418 & 147 & $54 \%$ \\
\hline 58 & 89 & 31 & $53 \%$ \\
\hline 136 & 202 & 66 & $49 \%$ \\
\hline 313 & 463 & 150 & $48 \%$ \\
\hline 615 & 907 & 292 & $47 \%$ \\
\hline 36 & 53 & 17 & $46 \%$ \\
\hline 9 & 12 & 4 & $45 \%$ \\
\hline 44 & 64 & 20 & $45 \%$ \\
\hline 13 & 19 & 6 & $45 \%$ \\
\hline 158 & 222 & 64 & $40 \%$ \\
\hline
\end{tabular}

* Numbers in thousands of jobs

(Source: Hecker, 2001) 


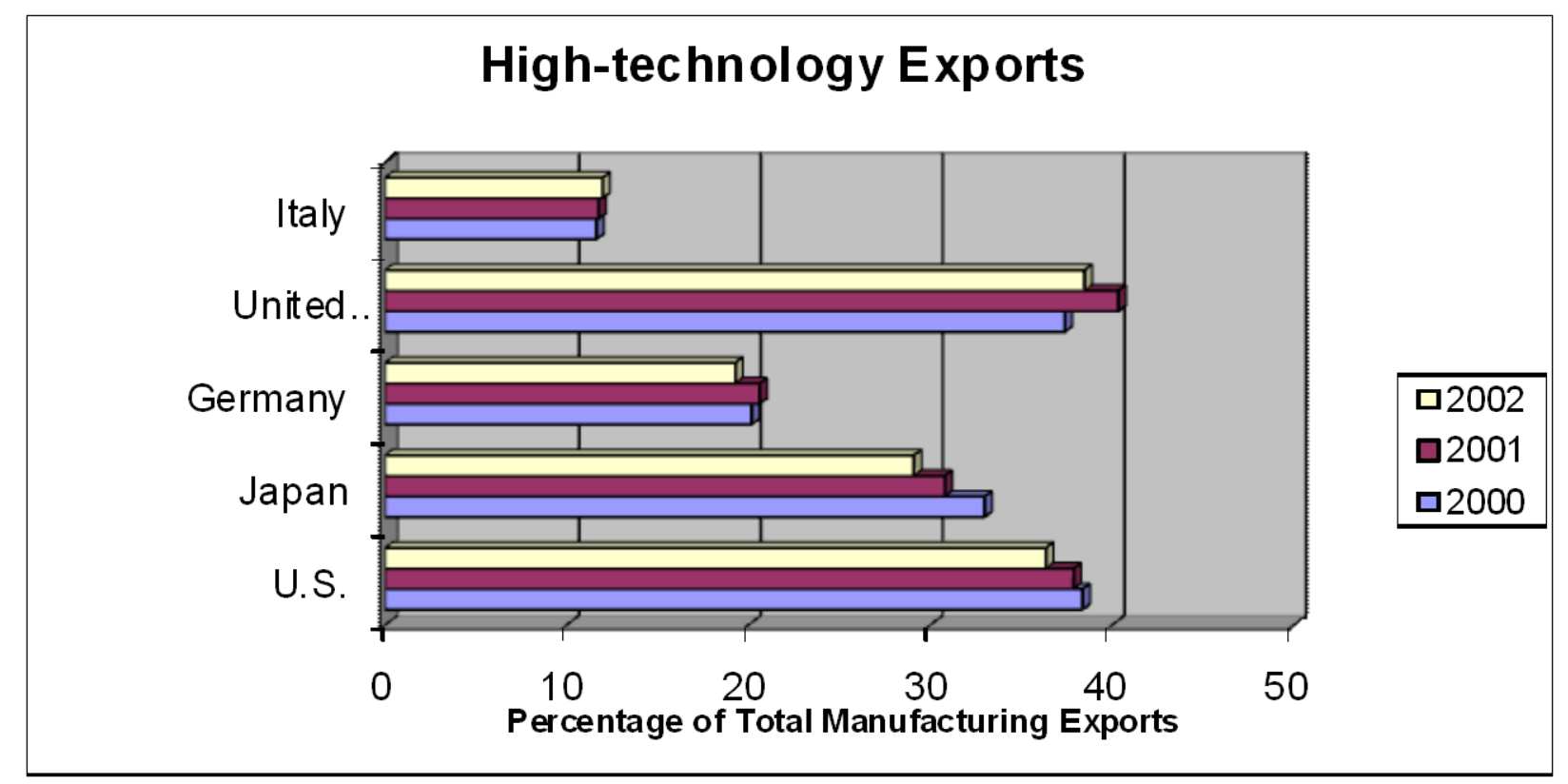

Source: OECD

\section{Global IT Services and Software by Region}

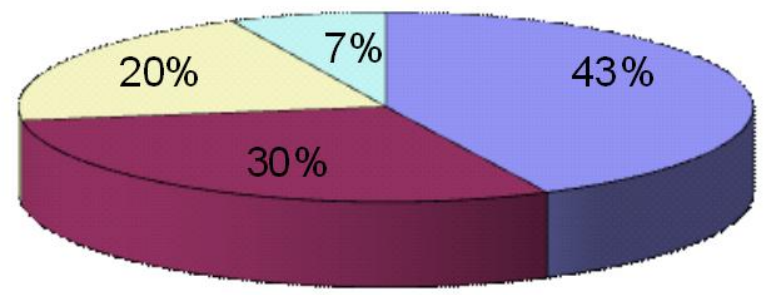

$\square$ North America

口Europe

口Asia-Pacific

口Rest of the World

Source: Datamonitor Market Research 


\section{Earned Degrees In Computer And Information Sciences}

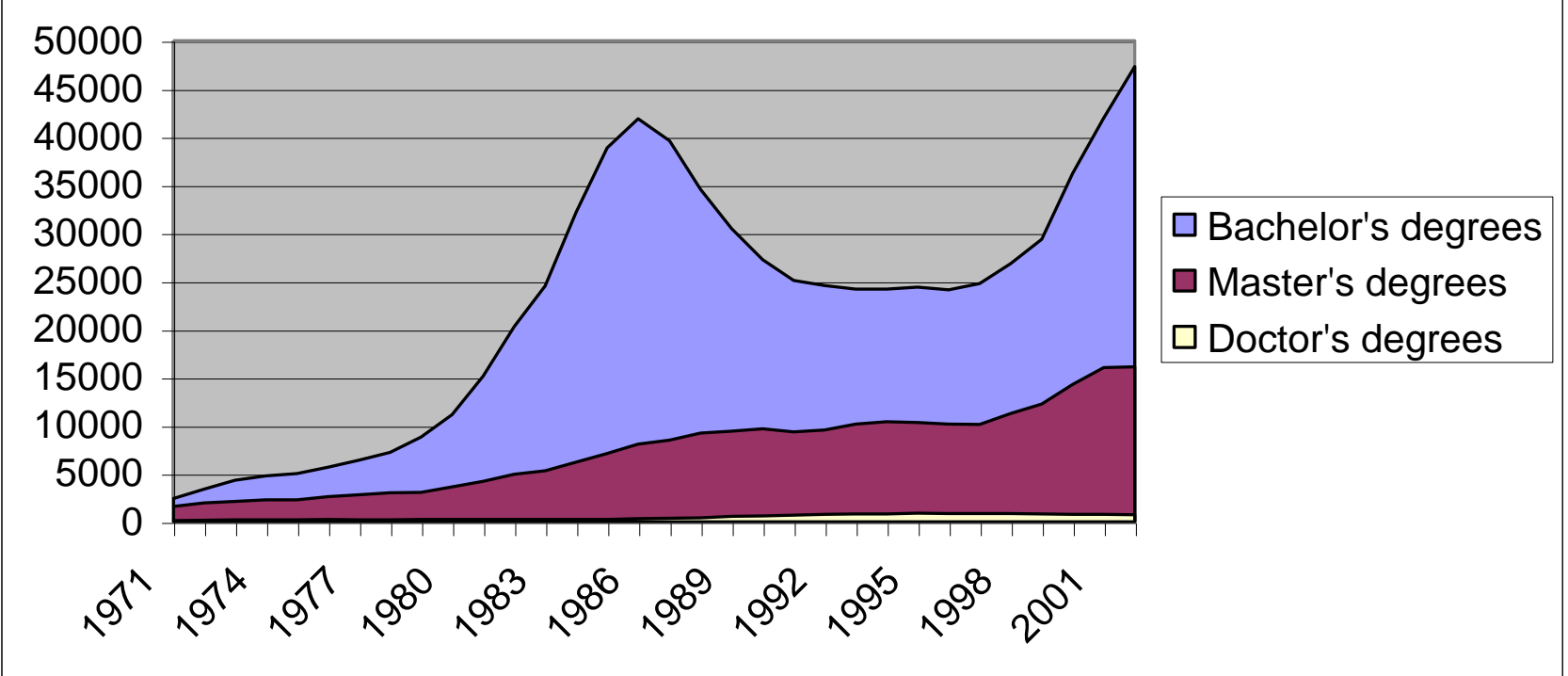

Source: Digest of Education Statistics

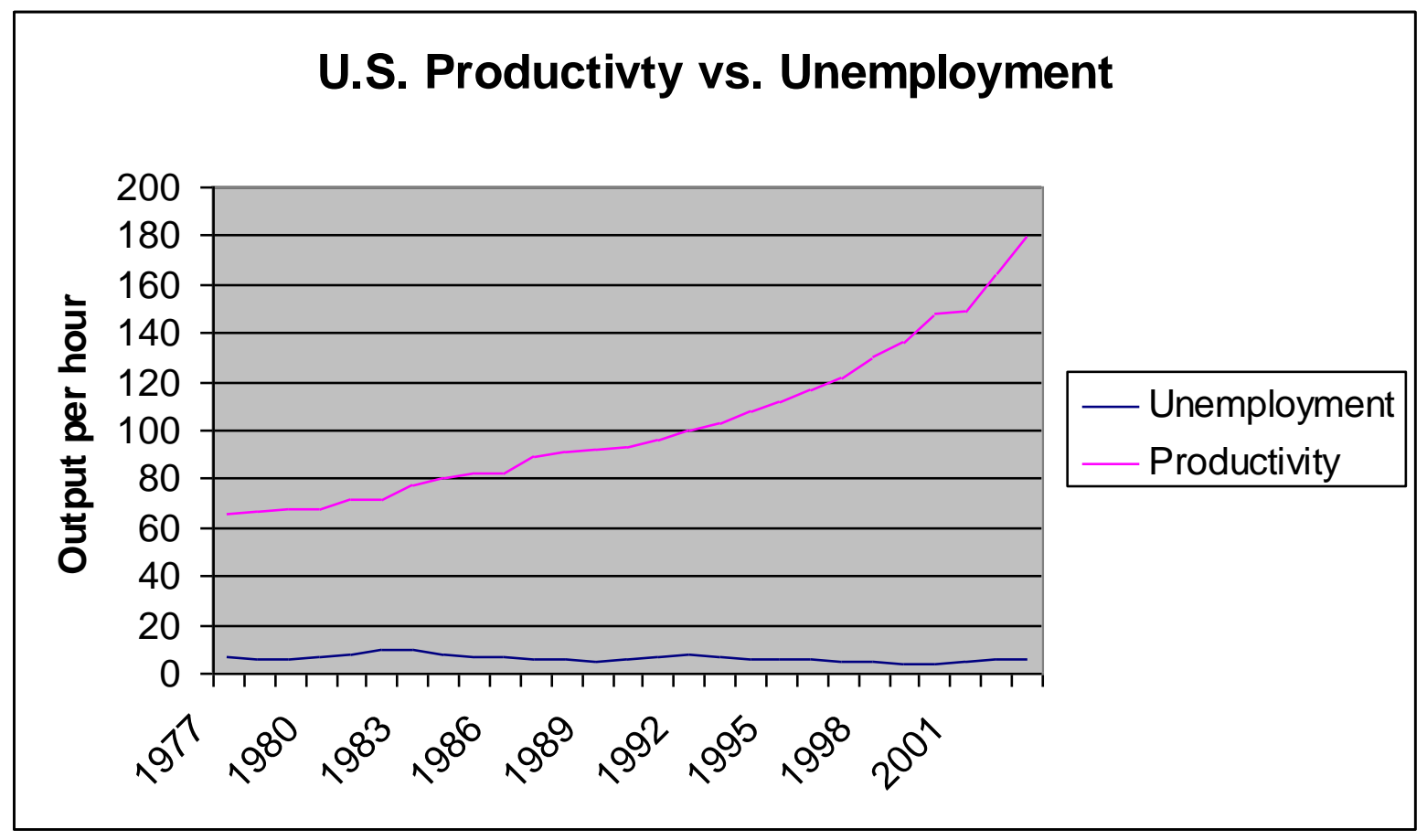

Source: Bureau of Labor Statistics 
U.S. International Payment for Computer and Information Services

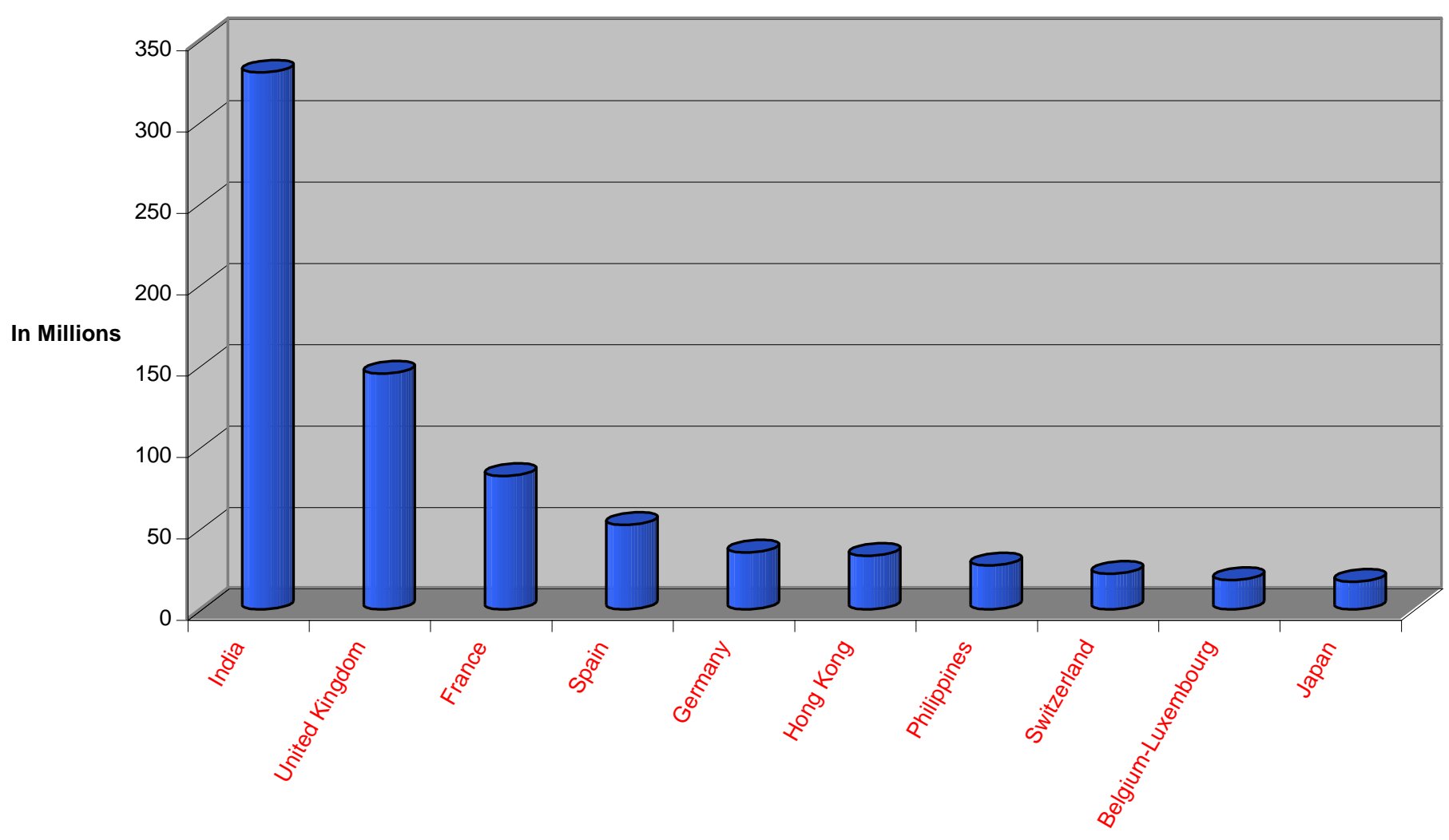

Source: U.S. Department of Commerce, Bureau of Economic Analysis, Balance of Payments Division. 


\section{Average Salary by Occupation}

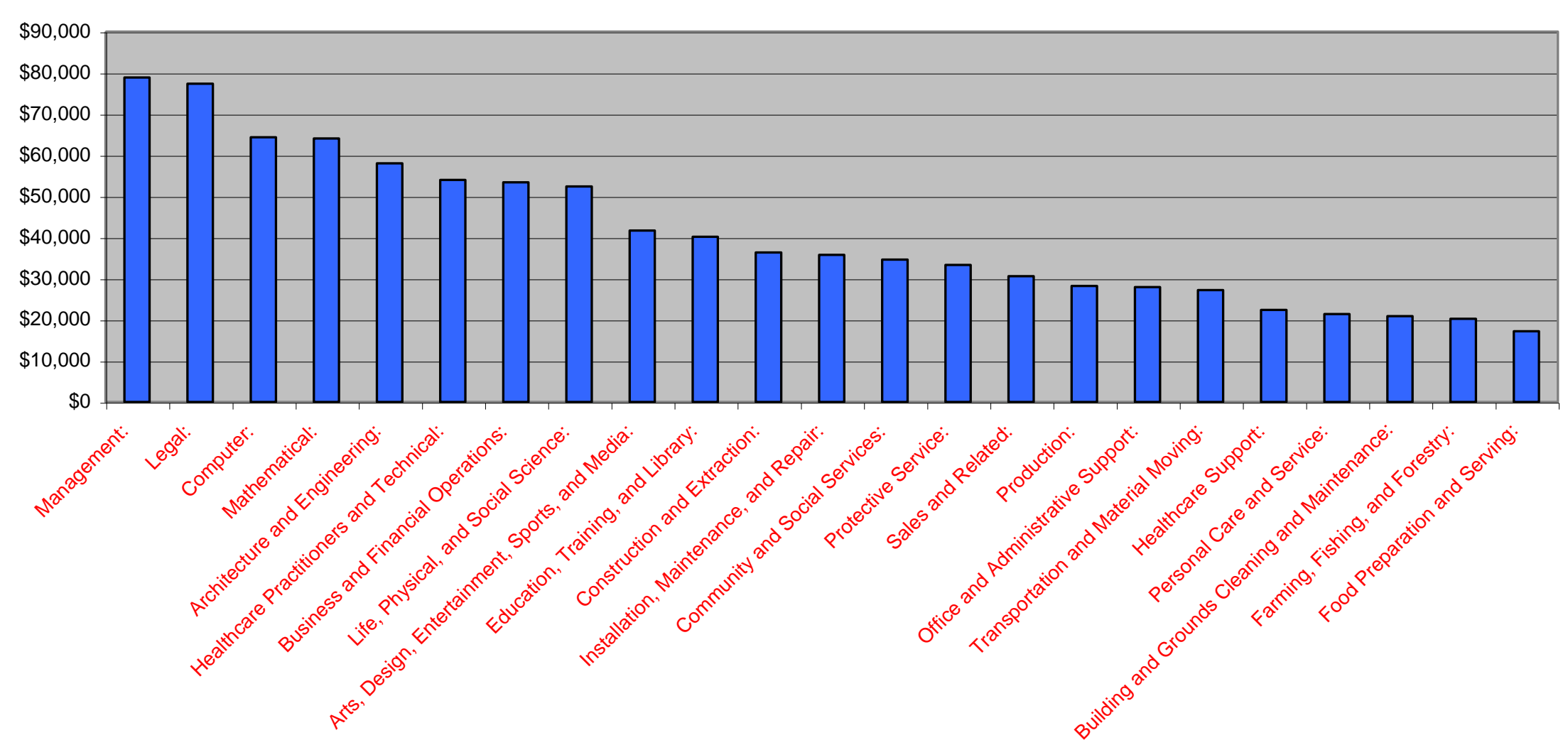




\section{REFERENCES}

1. Bureau of Labor Statistics. BLS Releases 2002-20012 Employment Projections.

2. Bureau of Labor Statistics. Professional and Related Fields. (2004).

3. Bureau of Labor Statistics, Tomorrow's Jobs, 2004-2005 Occupational Outlook Handbook.

4. Commerce, Education Announce Effort to Foster Advanced Technologies for Education and Training. (2003).

5. $\quad$ Datamonitor Industry Market Research. Global - Software \& Services. Nov 1, 2004.

6. Digest of Education Statistics. Department of Education, National Center for Education Statistics (2003).

7. $\quad$ Hecker. D., Occupational Employment Projections to 2010, Monthly Labor Review, 2001.

8. McCarthy John C., 3.3 million US Service Jobs To Go Offshore, Forrester Research, November 11, 2002.

9. Moran. R. T., Harris. P.R., and Stripp. W. G., (1993). Developing the Global Organization. Houston: Gulf Publications.

10. Organization for Economic Co-operation and Development. (2004).

11. U.S. Department of Commerce, Bureau of Economic Analysis, Balance of Payments Division. (2004).

12. U.S. Department of Commerce, Technology Administration. International Science and Technology Policies, Programs and Investments (2000).

13. U.S. Department of Commerce, Office of Technology Policy. America's New Deficit: The Shortage of Information Technology Workers. September, 1997.

\section{NOTES}

